\title{
PREPARATION AND MECHANICAL-ELECTRICAL PERFORMANCE OF CARBON FIBRE SENSING CONCRETE
}

\author{
"FANG YI, CHEN KAIQIN, ZHU MAN \\ Zhejiang Hongyan Detection Technology Co., Ltd. Hangzhou, Zhejiang, 311112 China \\ "E-mail: fangyi19831229@163.com
}

Submitted November 2, 2021; accepted November 29, 2021

\begin{abstract}
Keywords: Carbon fibre, Cement based, Resistivity, Strength, Freeze-thaw
Carbon fibre smart concrete is not only a promising type of structural materials, but also has prospective applications in fields that have special functional requirements. Here, the carbon fibre smart concrete was prepared by the extrusion moulding technique, and the resistivity, pressure-sensitive and temperature-sensitive characteristics were discussed as well as the freezing-thawing properties. The results show that the total porosity of the smart concrete decreases when the carbon fibre was added into a cement matrix, which is $15.72 \%$ in the case when carbon fibre content is $1.0 \mathrm{wt} . \%$. The resistivity of the smart concrete decreases quickly with the addition of carbon fibre, which gradually decreases with an increasing temperature and then gradually increases, and the critical transition temperature zone is in the range of $100-130{ }^{\circ} \mathrm{C}$. The compressive and flexural strengths of the smart concrete are the highest when the carbon fibre content is $0.6 \mathrm{wt}$. \%. The rate of change of the resistivity shows an obvious linear response under cyclic loading effects. The freeze-thaw resistance ability of the smart concrete with the addition of carbon fibres is better than that without carbon fibres, and the compressive strength reaches the highest level when the carbon fibre mass fraction is $0.6 \mathrm{wt} . \%$, which indicates that a suitable amount of carbon fibres can effectively restrict the damage to smart concrete induced by temperature stress.
\end{abstract}

\section{INTRODUCTION}

Cement is one of the most useful construction and building materials due to its good weather fastness characteristics, high compressive strength and low cost, etc., which has been widely used in kinds of construction buildings. Nowadays, with the development of modern multifunctional engineering processes, traditional cement-based materials face new challenges, kinds of novel concretes, such as self-sensing concrete, self-adaptive concrete, and self-healing concrete are becoming hot research topics worldwide [1-5].

It is known that carbon fibre has the characteristics of a high specific strength, specific elastic modulus, good anti-bending and shock resistance and superior conductivity, therefore, many scholars have conducted research on carbon fibre cement-based composites. The D.D.L Chung research group have conducted a large amount of work on these kinds of materials [6-11]. For example, M. Chiou et al. [6] found that the addition of short carbon fibres and chemical agents to Portland cement greatly increased the electromagnetic interference shielding effectiveness of the cement. S.H. Wen et al. $[7,8]$ observed the piezo-resistivity in cement-matrix composites with $2.6-7.4$ vol. \% unidirectional continuous carbon fibres, and provided the first theoretical model for piezo-resistivity phenomenon of carbon fibre cement-based materials, that is, pull-out of crackbridging fibres during crack. X.L. Fu et al. [9] found the self-monitoring behaviour of a carbon fibre reinforced mortar in two ways by curing age from 7 to 28 days. In the field of fabrication methods, many scholars have also conducted research [12-16]. For example, X. Cheng et al. [12] fabricated a carbon fibre sulfoaluminate cement composite by casting, extrusion, and pressing processes, and discussed the piezo-conductance effect of the composites. S.F. Huang et al. [13] fabricated carbon fibre reinforced cement-based composites by the compressing method, and found a remarkable negative temperature coefficient and a positive temperature coefficient in the composite. B. Chen et al. [14] investigated the influence of the carbon fibre volume, size, cement-based matrix, relative humidity and curing age on the characteristic of carbon fibre cement-based composites, and offered a basic theory for smart cement-based composites.

In addition, in the field of sensing characteristics, many scholars have also conducted research [17-25]. For example, Z.F. Liu et al. [17] introduced ferroferric oxide $\left(\mathrm{Fe}_{3} \mathrm{O}_{4}\right)$ nanoparticles into carbon fibre $(\mathrm{CF}) /$ cement composites to enhance the electromagnetic interference shielding effectiveness. Aimed at solving the electromagnetic pollution problem, Z.J. Wang et al. [18] investigated the reflectivity variation of the composites against the wave before and after 50 freeze- 
thaw cycles at $2.0-18.0 \mathrm{GHz}$ frequency bands. B.G. Han et al. [19] prepared a kind of carbon fibre cement paste piezoresistive sensors made of a piezoresistant carbon fibre cement paste, which were mainly used for the local monitoring of concrete structures. J.Q. Zuo et al. [20] added carbon nanotubes into a carbon fibre cement system and studied the pressure-sensitive and temperature-sensitive properties of the carbon nanotubecarbon fibre/cement nanocomposites. H. Wang et al. [21] studied the multi-functional properties of carbon nanofibre reinforced reactive powder concrete.

In short, carbon fibre cement-based composites show good potential in smart concrete fields. In this paper, extrusion moulding was used to fabricate carbon fibre cement-based composites by using Portland cement as the matrix and short carbon fibres as the functional component. The morphology, resistivity, compressive strength, pressure-sensitive and temperature-sensitive, and freeze-thaw properties were discussed.

\section{EXPERIMENTAL}

Raw materials

A commercial P.O. 42.5R cement was used as the matrix for the carbon fibre cement-based composites, as shown in Table 1. The isotropic PAN-based short carbon fibre was used as the functional component, as shown in Table 2. In order to improve the effective dispersion of carbon fibres in the cement matrix, a commercial carboxymethyl cellulose was used as a dispersant. In addition, a polycarboxylate superplasticiser with a solid content of $30 \%$ and hydroxypropyl methylcellulose with a viscosity of $2 \times 105 \mathrm{mPa} \cdot \mathrm{s}$ were also used for the extrusion moulding technique.
Fabrication of carbon fibre smart concrete

The cement, water and carbon fibre were weighed according to the water to cement ratio of 0.25 . Then, the carboxymethyl cellulose dispersant in the amount of $0.4 \%$ by weight of cement was dissolved into the water with continuous stirring for $10 \mathrm{~min}$ until completely dissolved. Carbon fibres in the amount of 0 wt. \%, 0.3 wt. $\%, 0.6$ wt. $\%$ and 1.0 wt. $\%$ by weight of cement were gradually added into the solution with continuous stirring. Then the cement, water solution with carbon fibre, hydroxypropyl methylcellulose in the amount of 0.8 wt. \% by weight of cement and polycarboxylate superplasticiser in the amount of $0.5 \mathrm{wt}$. \% by weight of cement were mixed together in the mixer for $3 \mathrm{~min}$. Then the plastic mixture was put into an extruding machine to prepare the cylindrical smart concrete samples. After extrusion, the specimens were put into a moist-curing room (temperature $20 \pm 1^{\circ} \mathrm{C}$, relative humidity $\geq 95 \%$ ) for 28 days. Finally, the cylindrical smart concrete samples of $\varphi 20 \mathrm{~mm} \times 3 \mathrm{~mm}$ were machined by using a diamond cutter. The smart concrete composition details are shown in Table 3.

\section{Performance test}

The porosity of the carbon fibre smart concrete was tested by using a mercury injection apparatus (Poremaster-60, Quantachrome, USA). Scanning electronic microscopy (S-2500, Hitachi, Japan) was used to observe the micrographs of the samples, and an X-ray diffractometer (D8 Advance, Bruker, Germany) was used to perform the structural analysis of the cement hardened paste.

Both surfaces of the carbon fibre smart concrete were polished by using sand paper, and then ethyl alcohol was used to clean the polished surfaces. Conductive

Table 1. Basic cement properties.

\begin{tabular}{|c|c|c|c|c|c|c|}
\hline \multirow[t]{2}{*}{$\begin{array}{l}\text { Water requirement } \\
\text { of normal consistency }(\%)\end{array}$} & \multicolumn{2}{|c|}{$\begin{array}{c}\text { Setting time } \\
(\mathrm{min})\end{array}$} & \multicolumn{2}{|c|}{$\begin{array}{l}\text { Compressive strength } \\
\text { (MPa) }\end{array}$} & \multicolumn{2}{|c|}{$\begin{array}{l}\text { Bending strength } \\
(\mathrm{MPa})\end{array}$} \\
\hline & Initial setting & Final setting & $3 d$ & $28 \mathrm{~d}$ & $3 \mathrm{~d}$ & $28 \mathrm{~d}$ \\
\hline 28 & 130 & 220 & 25.0 & 50.0 & 6.3 & 9.2 \\
\hline
\end{tabular}

Table 2. Properties of the carbon fibre.

\begin{tabular}{lccccc}
\hline $\begin{array}{l}\text { Diameter } \\
(\mu \mathrm{m})\end{array}$ & $\begin{array}{c}\text { Length } \\
(\mathrm{mm})\end{array}$ & $\begin{array}{c}\text { Tensile strength } \\
(\mathrm{MPa})\end{array}$ & $\begin{array}{c}\text { Elastic modulus } \\
(\mathrm{GPa})\end{array}$ & $\begin{array}{c}\text { Elongation at break } \\
(\%)\end{array}$ & $\begin{array}{c}\text { Density } \\
\left(\mathrm{g} \cdot \mathrm{cm}^{-3}\right)\end{array}$ \\
\hline $7.0-7.4$ & $5 \sim 10$ & $5.48 \times 103$ & 294 & 1.5 & 1.79 \\
\hline
\end{tabular}

Table 3. Smart concrete composition (g).

\begin{tabular}{lcccccc}
\hline Number & Cement & Water & Water reducer & Superplasticiser & Dispersant & Carbon fibre \\
\hline CF0 & 500 & 125 & 4 & 2.5 & 2 & 0 \\
CF3 & 500 & 125 & 4 & 2.5 & 2 & 1.5 \\
CF6 & 500 & 125 & 4 & 2.5 & 2 & 3.0 \\
CF10 & 500 & 125 & 4 & 2.5 & 2 & 5.0 \\
\hline
\end{tabular}


silver paste was then coated on both surfaces as the electrode. The resistance of the samples was tested by using a digital electric bridge, and the average value of the resistance after five tests was used as the final resistance of the samples. The samples were put into low/high temperature test chambers for the resistance-temperature characteristic test by using a self-made test fixture, and the testing temperature range was $-40{ }^{\circ} \mathrm{C} \sim 150{ }^{\circ} \mathrm{C}$.

The mechanical properties of the samples after curing for $28 \mathrm{~d}$ were test by using compression and flexure testing machines. The mechanical-resistance characteristics of the samples were tested by using an electronic universal testing machine (5569A, Instron, USA) with the loading direction vertical to the electrode area.

A freeze-thaw experiment was also conducted to check the resistance variation of the carbon fibre concrete under freeze-thaw damage. The samples were first put into the refrigerator at $-20{ }^{\circ} \mathrm{C}$ for $3 \mathrm{~h}$, and then taken out from the refrigerator and put into a drying oven at $70{ }^{\circ} \mathrm{C}$ for another $3 \mathrm{~h}$. The resistance was tested every five freeze-thaw cycles. A total of fifteen freeze-thaw cycles were conducted in this paper.

\section{RESULTS AND DISCUSSION}

\section{Microstructure analysis}

Figure 1 shows the X-ray diffraction spectra of the smart concrete with different carbon fibre mass fractions after curing for $3 \mathrm{~d}$. It can be seen that obvious diffraction peaks of hydration products of $\mathrm{Ca}(\mathrm{OH})_{2}$ exist in the hardened cement paste as well as diffraction peaks of the cement minerals, such as $\mathrm{C}_{3} \mathrm{~S}, \mathrm{C}_{2} \mathrm{~S}$, and the addition of carbon fibre has little influence on the cement hydration behaviour.

Figure $1 \mathrm{X}$ ray diffraction spectra of the smart concrete with different carbon fibre mass fractions

The cement constituents after hydration includes hydration products, such as $\mathrm{CSH}$ gel and $\mathrm{Ca}(\mathrm{OH})_{2}$,

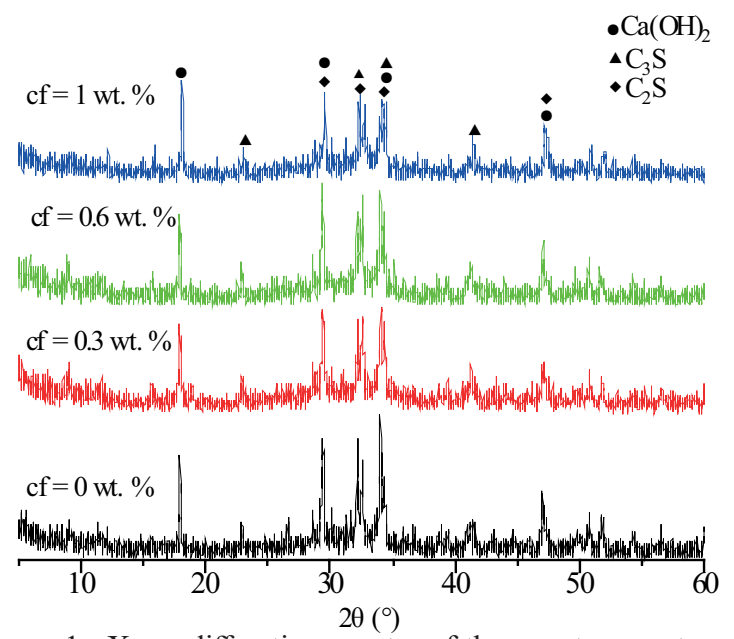

Figure 1. X ray diffraction spectra of the smart concrete with different carbon fibre mass fractions unhydrated minerals, carbon fibre, water and pores, etc., which is a gas-liquid-solid three-phase porous system. The pore structure, such as the pore dimension, distribution and porosity have great influence on the compactness, impermeability and pressure-sensitivity characteristics of the carbon fibre smart concrete. Figure 2 shows the pore distribution of the carbon fibre smart concrete cured for $28 \mathrm{~d}$. It can be seen that the pore diameter is mainly in the range of $0.1 \mu \mathrm{m}$. When the carbon fibre mass fraction is $0 \mathrm{wt} . \%, 0.3 \mathrm{wt} . \%, 0.6 \mathrm{wt} . \%$ and $1.0 \mathrm{wt} . \%$, the density of the samples is $1.73 \mathrm{~g} \cdot \mathrm{cm}^{-3}$, $1.81 \mathrm{~g} \cdot \mathrm{cm}^{-3}, 1.82 \mathrm{~g} \cdot \mathrm{cm}^{-3}$ and $2.01 \mathrm{~g} \cdot \mathrm{cm}^{-3}$, respectively, and the total porosity is $23.00 \%, 22.17 \%, 20.47 \%$ and $15.72 \%$, respectively. The most probable pore size is $0.05-0.08 \mu \mathrm{m}$ when the carbon fibre mass fraction is less than 0.6 wt. $\%$, and is $0.002-0.05 \mu \mathrm{m}$ when the carbon fibre mass fraction is $1.0 \mathrm{wt} . \%$. This indicates that the macropores in the hardened cement paste are effectively restricted with the carbon fibre addition.

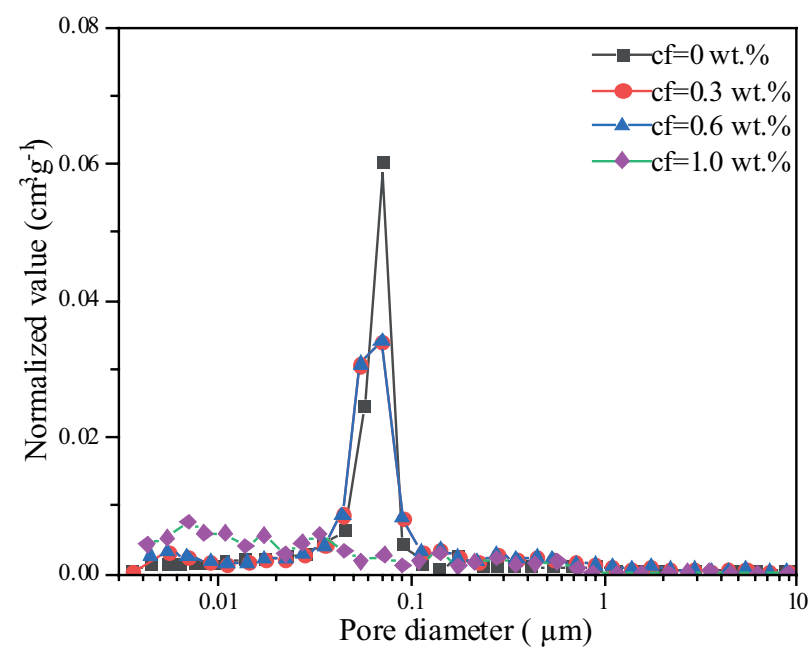

Figure 2. Pore diameter distribution of the smart concrete with different carbon fibre contents.

Figure 3 shows the SEM photos of the smart concrete with different carbon fibre contents. It can be seen that when the carbon fibre content is low, the carbon fibres distribute randomly in the hardened cement paste, and there is no contact among the fibres. When increasing the carbon fibre content, the carbon fibre cluster can be observed in Figure $3 \mathrm{~b}$ and c. As a superplasticiser, dispersant and plasticiser were used to improve the extrusion moulding technique, a certain amount of pores will also be induced due to the addition of the admixtures, which inevitably affects the strength and conductivity of the carbon fibre smart concrete.

\section{Resistivity-temperature characteristics}

Figure 4 shows the resistivity variation curves of the smart concrete with different carbon fibre contents. It can be seen that the resistivity decreases quickly after the 

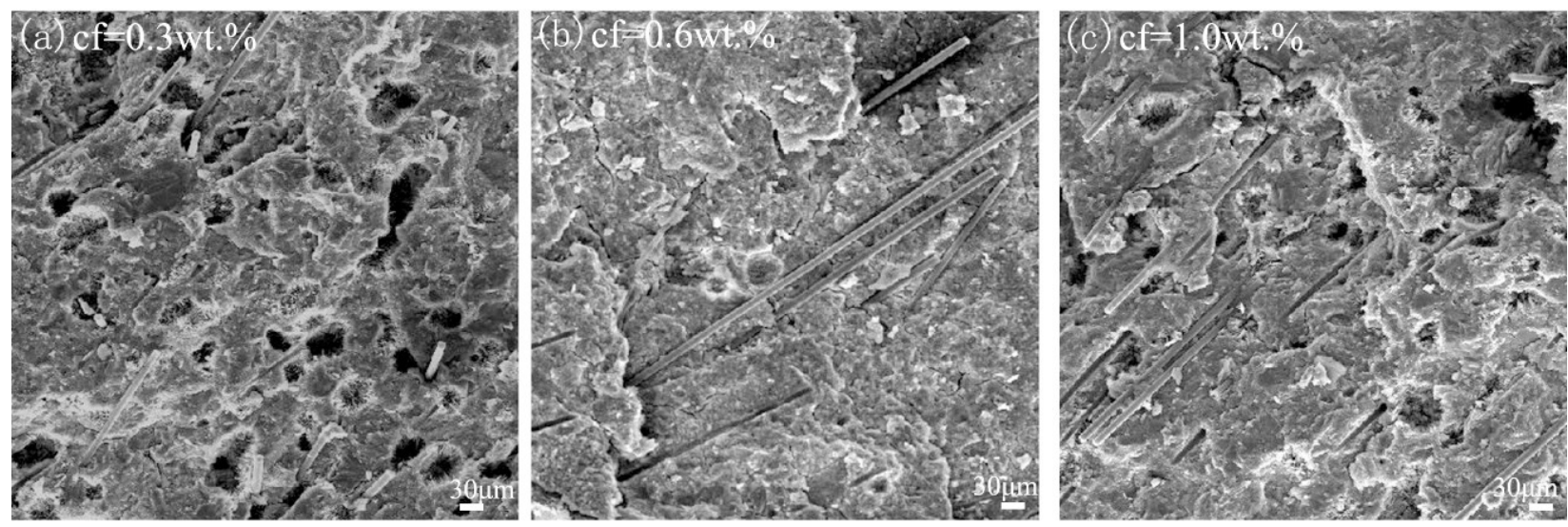

Figure 3. SEM photos of the smart concrete with different carbon fibre contents.

addition of carbon fibre and gradually slows down with an increasing carbon fibre content. It is well known that hardened cement paste is an insulator, however, carbon fibre is conductor. Therefore, when the carbon fibre combines with the cement paste, the resistance of the carbon fibre smart concrete consists of two parts, that is, tunnel resistance composed of many tiny tunnel energy barriers and the resistance of the carbon fibre. The larger the carbon fibre content, the larger the contribution of the carbon fibre has on the resistance of the smart concrete; therefore, the resistivity gradually decreases with an increasing carbon fibre content.

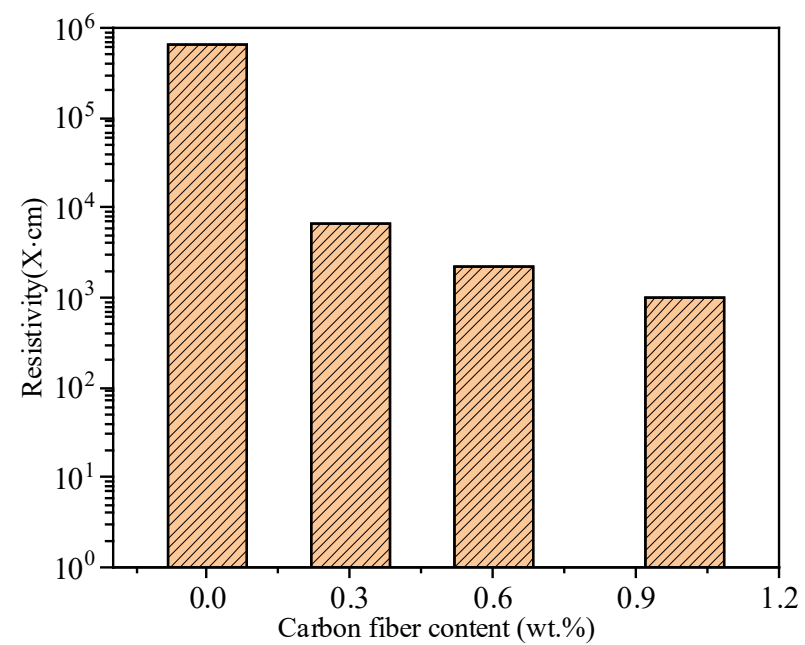

Figure 4. Relationship of resistivity of the smart concrete as a function of the carbon fibre content.

In addition, it is known that, based on the percolation theory $[7,8]$, when the volume fraction of a conductive component is less than a threshold value, the resistivity of the composite will slowly decrease with an increase in the conductive component, which decreases sharply when the volume fraction of the conductive component reaches the threshold value and then decreases smoothly. When increasing the carbon fibre content, the conductive network forms among the carbon fibres, therefore, the resistivity of the smart concrete decreases. When carbon fibre content increases toward the threshold value, the conductive network increases greatly, and the resistivity also obviously decreases. After that, although the increase in the carbon fibre content further improves the conductive network, the resistivity shows a slowly decreasing trend.

Figure 5 is a variation curve of the resistivity of the carbon fibre smart concrete with temperature. It can be seen that it shows good resistivity-temperature characteristics, that is, the resistivity decreases gradually with an increasing temperature and then increases gradually. The resistivity is the lowest when temperature is in the range of $100-130^{\circ} \mathrm{C}$, which is called the critical transition temperature zone. Based on the tunnel effect theory [8], when the temperature rises, the electrons in the energy band absorb the energy and they become carriers, which jump among the carbon fibres and realise the electronic transportation. Therefore, the resistivity of the samples decreases, that is, has a negative resistance coefficient (NTC) effect. When the temperature further increases, inner stress between the carbon fibres and cement matrix appears due to the thermal expansion from the cement matrix, which causes the relative movement

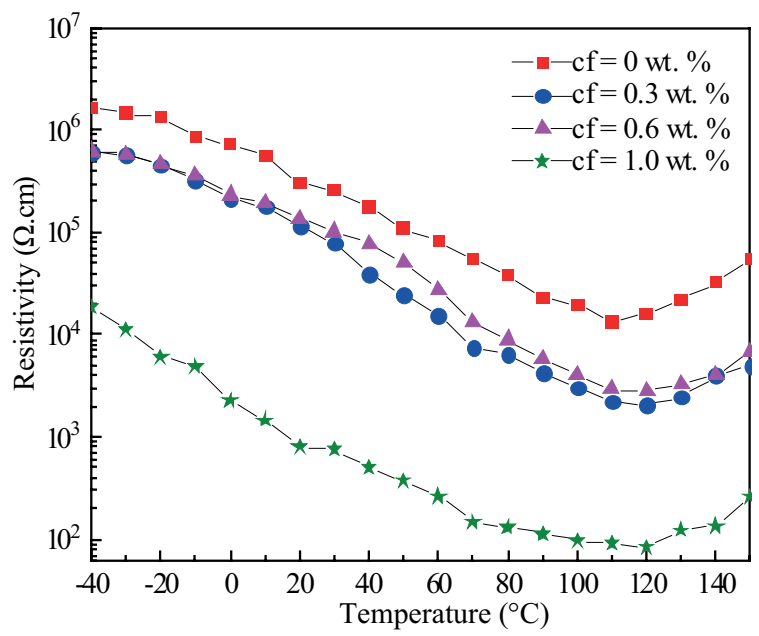

Figure 5. Variation in the resistivity of the smart concrete with the temperature. 
of the carbon fibres and breaks the conductive network. In addition, the water in the smart concrete decreases with an increasing temperature, which will also result in an increase in the resistivity [26]. Therefore, the resistivity of the samples increases, that is, has a positive resistance coefficient (PTC) effect.

In addition, it can also be seen from Figure 6 that the resistivity of the samples with the carbon fibres is obviously less than that without the carbon fibres, especially when the carbon fibre content is $1.0 \mathrm{wt} . \%$, the resistivity of smart concrete obviously decreases. The probable reason is that when the carbon fibre content is large enough, the conductive process of the samples mainly relies on the interconnection of the carbon fibres in the cement matrix, therefore, the resistivity decreases greatly.

\section{Resistivity-mechanical properties}

Figure 6 shows the compressive strength and flexural strength of the smart concrete with different carbon fibre contents. It can be seen that the compressive and flexural strengths of the samples when the carbon fibre content is 0.3 wt. $\%$ are $40 \%$ and $51 \%$, respectively, which are larger than that without the carbon fibres. With a further increase in the carbon fibre content, the compressive strength tends to be steady, and when the carbon fibre content is 1.0 wt. \%, a slow decrease in the compressive strength can be seen. The compressive and flexural strengths of the samples reach the highest level when the carbon fibre content is $0.6 \mathrm{wt}$. \%. The reason is probably that the carbon fibres are not well dispersed in the cement matrix when the carbon fibre is large [27], and the inner defects and broken carbon fibres during the extruding process might also affect the compressive strength.

It is known that some microcracks in hardened cement paste exist, which spread under loading effects. When carbon fibres are added, the expansion of

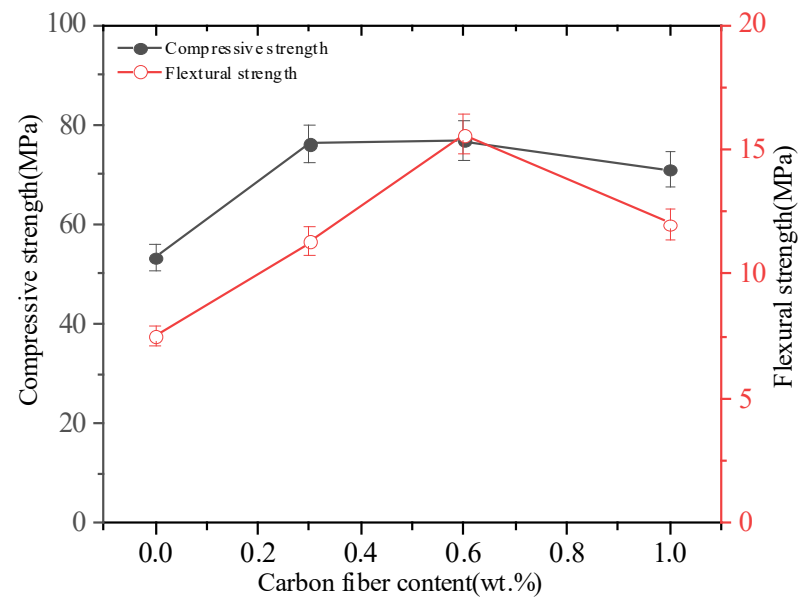

Figure 6. Compressive and flexural strengths of the smart concrete with different carbon fibre contents. microcracks will be restricted due to the bridge effects of the carbon fibres. Therefore, toughening and reinforcing advantages can be realised because the carbon fibres absorb large amounts of energy during the pulling-out process. Carbon fibre smart concrete is a kind of fibre reinforced composite, the interfacial characteristic between the carbon fibres and the cement matrix has great influence on the mechanical properties of the smart concrete. When the carbon fibre content is low, the influence of the interface between the carbon fibres and the cement matrix on the strength is far less than the toughening and reinforcing effect of the fibres on the matrix. When the carbon fibre content is high, the interface between the fibres and the matrix increases, which decreases the reinforcing effect of the carbon fibres on the samples. With a further increase in the the carbon fibre content, the influence of the interface on the mechanical properties becomes more important, and meanwhile the moulding property of the samples also decreases, which obviously decreases the reinforcing effect.

Figure 7 shows the variation curves of the rate of change in the resistivity of the smart concrete with the 0.6 wt. $\%$ carbon fibre as a function of stress. It can be seen that under the cyclic loading effects, there is an obvious corresponding relationship between the rate of change in the resistivity and loading. The rate of change in the resistivity increases linearly with an increasing in the loading and decreases quickly when the loading is removed. Furthermore, when increasing the cyclic times, there is a good repetitiveness between the rate of change in the resistivity and loading.

The probable reason of above the resistivitymechanical phenomena is that the chance of the carbon fibres in the cement matrix contacting each other increases under loading effects, therefore, a new conductive network occurs, which leads to a decrease in the resistivity. When the loading is removed, the energy barrier among the carbon fibres decreases, therefore, the existing conductive network is broken, which leads to an

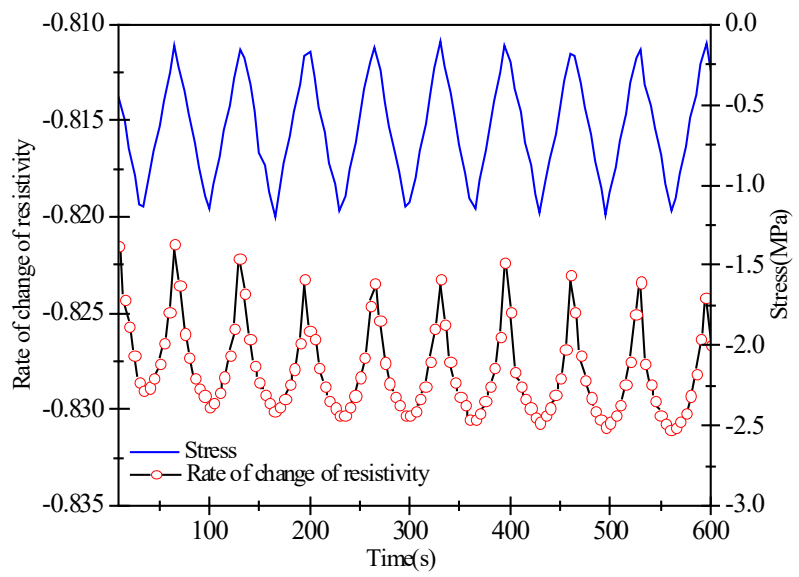

Figure 7. Variation in the rate of change in the resistivity of the smart concrete with $0.6 \mathrm{wt} . \%$ carbon fibre vs. stress 
increase in the resistivity of the smart concrete. Because the smart concrete is at an elastic deformation stage under a small loading extent, the reconstruction and formation of the conductive network plays a leading role, accordingly, the resistivity shows reversible variation with the loading and unloading.

\section{Compressive strength and resistivity under freeze-thaw effects}

Figure 8 shows the compressive strength of the smart concrete with different carbon fibre contents before and after 20 freeze-thaw cycles. It can be seen that the compressive strength remarkably decreases after the freezing-thawing, especially the samples without the carbon fibres. It is known that the water that exists in the pores of a hardened cement paste will generate expansion stress under freezing, and the stress will be released when the temperature rises. In addition, the salt solutions that exist in the pores will also affect the freezing-thawing properties of the smart concrete [28]. Therefore, local cracking will appear in the samples under repeated freezing-thawing effects, which accordingly leads to the destruction of the concrete and causes a decrease in the compressive strength.

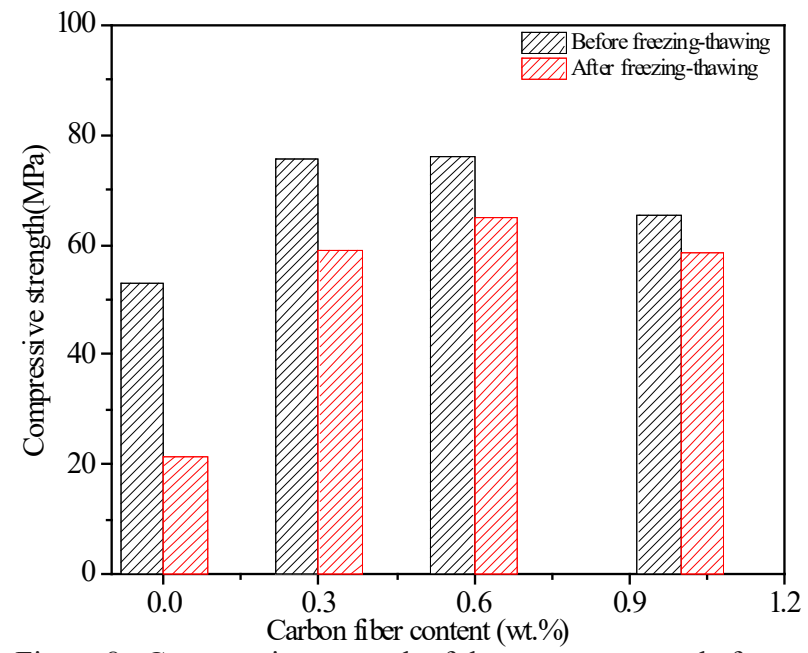

Figure 8. Compressive strength of the smart concrete before and after the freezing-thawing

In addition, it also can be found through comparison that the freeze-thaw resistance ability of the smart concrete with the addition of carbon fibres is better than that without the carbon fibres. With the increasing carbon fibre content, the decreased percentage of strength of the smart concrete is $59.45 \%, 22.22 \%, 14.56 \%$ and $10.35 \%$, respectively. When the carbon fibre mass fraction is 1.0 wt. $\%$, the strength loss of the smart concrete is at a minimum, which indicates that a suitable carbon amount of fibre can effectively restrict the destruction of the smart concrete induced by temperature stress.
Figure 9 shows the variation curve in the resistivity of the smart concrete with the different carbon fibre content as a function of the freeze-thaw cycles. It can be seen that with an increase in the freeze-thaw cycles, the resistivity of the smart concrete shows an increasing trend. Because the conductive characteristics of the smart concrete depends on the carbon fibres, the cement matrix and water in the pores, the probable reason of the above phenomena is that the conductivity contributed by the water decreases due to the water loss under a repeating freezing-thawing effect. On the other hand, the microcracks increase under the repeated temperature variation, which destroys the conductive network formed by the carbon fibres and causes an increase in the resistivity.

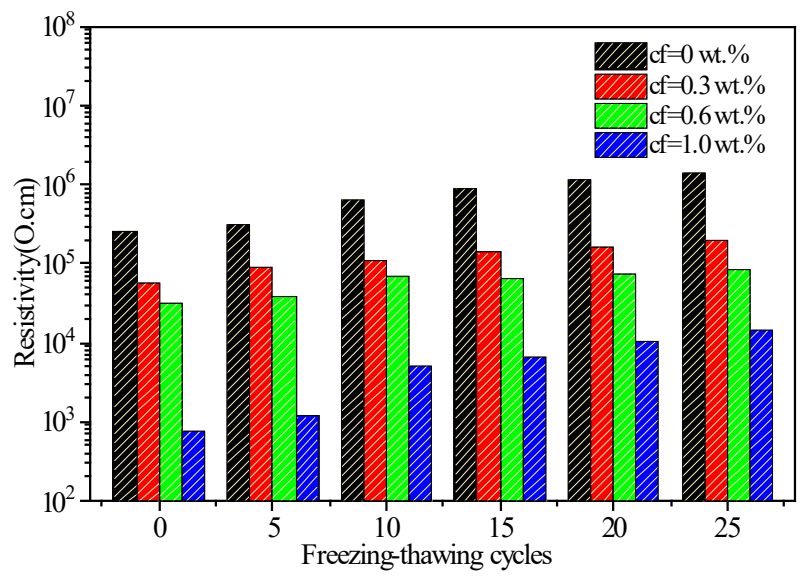

Figure 9. Resistivity variation of the smart concrete as a function of the freeze-thaw cycles

In addition, it also can be found through comparison that with an increase in the freeze-thaw cycles, the increasing extent of the resistivity of the smart concrete with a carbon fibre content of 0.3 wt. $\%$ and 0.6 wt. $\%$ is smooth, however, that of the samples without the carbon fibre and a carbon fibre content of 1.0 wt.\% obviously increases. Especially when ten freeze-thaw cycles are reached, the resistivity increases remarkably, which might be attributed to the water loss and broken carbon fibre conductive network.

\section{CONCLUSIONS}

In this paper, extrusion moulding was used to fabricate carbon fibre cement-based composites by using Portland cement as the matrix and short carbon fibres as the functional component, and the following conclusions can be drawn:

(1) the total porosity of the smart concrete decreases when carbon fibres were added into the cement matrix, which was $15.72 \%$ when the carbon fibre content was 1.0 wt. $\%$. The most probable pore size is $0.05-0.08 \mu \mathrm{m}$ when the carbon fibre mass fraction is less than 0.6 wt. $\%$, and is $0.002-0.05 \mu \mathrm{m}$ when the carbon fibre mass fraction is $1.0 \mathrm{wt} . \%$. 
(2) the resistivity of the smart concrete decreases quickly with the addition of carbon fibres, which gradually decreases with an increasing temperature and then gradually increases, and the critical transition temperature zone is in the range of $100-130{ }^{\circ} \mathrm{C}$. The compressive and flexural strengths, when the carbon fibre content is 0.3 wt. $\%$ are $40 \%$ and $51 \%$, are larger than that without carbon fibres, respectively. The compressive and flexural strengths of the smart concrete reach the highest levels when the carbon fibre content is $0.6 \mathrm{wt}$. \%.

(3) the rate of change in the resistivity shows an obvious linear response under cyclic loading effects. The freeze-thaw resistance ability of the smart concrete with the addition of carbon fibres is better than that without the carbon fibres, and the compressive strength loss of the smart concrete is at a minimum when the carbon fibre mass fraction is $1.0 \mathrm{wt} . \%$.

\section{REFERENCES}

1. Chung D.D.L. (2001): Electromagnetic interference shielding effectiveness of carbon materials. Carbon, 39, 279-285. doi: 10.1016/S0008-6223(00)00184-6

2. Song G.B., Gu H.C., Mo Y.L. (2008):Smart aggregates: multi-functional sensors for concrete structures-a tutorial and a review. Smart Materials and Structures, 17(3), 033001.

3. Li Z.J., Zhang D., Wu K.R. (2002): Cement-based 0-3 piezoelectric composites. Journal of the American Ceramic Society, 85(2), 305-313. doi: 10.1111/j.1151-2916.2002. tb00089.x

4. Vijay K., Murmu M., Deo S.V.(2017): Bacteria based self healing concrete-A review. Construction and Building Materials, 152, 1008-1014.doi: 10.1016/j. conbuildmat.2017.07.040

5. Sun M.Q., Li Z.Q., Liu Q.P., Tang Z.G., Shen D.R. (2000): A study on thermal self-diagnostic and self-adaptive smart concrete structures. Cement and Concrete Research, 30(8), 1251-1253.doi: 10.1016/S0008-8846(00)00284-2

6. Chiou J.M., Zheng Q., Chung D.D.L. (1989): Electromagnetic interference shielding by carbon fibre reinforced cement. Composites, 20, 379-381. doi: 10.1016/0010-4361(89)90663-0

7. Wen S.H., Chung D.D.L. (1999): Piezoresistivity in continuous carbon fiber cement-matrix composite. Cement and Concrete Research, 29, 445-449. doi: 10.1016/S00088846(98)00211-7

8. Wen S.H., Chung D.D.L. (2006): Model of piezoresistivity in carbon fiber cement. Cement and Concrete Research, 36, 1879-1885. doi: 10.1016/j.cemconres.2006.03.029

9. Fu X.L., Chung D.D.L. (1997): Effect of curing age on the self-monitoring behavior of carbon fiber reinforced mortar. Cement and Concrete Research, 27, 1313-1318. doi: 10.1016/S0008-8846(97)00118-X

10. Muthusamy S., Chung D. D. L. (2010): Carbon-fiber cement-based materials for electromagnetic shielding. $A C I$ Materials Journal, 107(6), 602-610.

11. Xu Y.S., Chung D.D.L. (2001): Silane-treated carbon fiber for reinforcing cement. Carbon, 39, 1995-2001. doi: 10.1016/S0008-6223(01)00028-8

12. Cheng X., Wang S.D., Lu L.C., Huang S.F. (2011):
Influence of preparation process on piezo-conductance effect of carbon fiber sulfoaluminate cement composite. Journal of Composite Materials, 45(20), 2033-2037.doi: 10.1177/0021998311407990

13. Huang S.F., Xu D.Y., Chang J., Xu R.H., Lu L.C., Cheng X. (2007): Smart properties of carbon fiber reinforced cementbased composites. Journal of Composite Materials, 41, 125-131. doi: 10.1177/0021998306063378

14. Chen B., Wu K.R., Yao W. (2004): Conductivity of carbon fiber reinforced cement-based composites. Cement and Concrete Composites, 26(4), 291-297. doi: 10.1016/S09589465(02)00138-5

15. Park S. B., Lee B. I., Lim Y. S. (1991): Experimental study on the engineering properties of carbon fiber reinforced cement composites. Cement and Concrete Research, 21, 589-600. doi: 10.1016/0008-8846(91)90110-4

16. Wang C., Jiao G.S., Li B.L., Peng L., Feng Y., Gao N., Li K.Z. (2017): Dispersion of carbon fibers and conductivity of carbon fiber-reinforced cement-based composites. Ceramics International, 43(17), 15122-15132. doi: 10.1016/j.ceramint.2017.08.041

17. Liu Z.F., Ge H.Y., Wu J.M., Chen J. (2017): Enhanced electromagnetic interference shielding of carbon fiber/cement composites by adding ferroferric oxide nanoparticles. Construction and Building Materials, 151, 575-581.doi: 10.1016/j.conbuildmat.2017.06.017

18. Wang Z. J., Li K.Z., Wang C. (2014): Freezingthawing effects on electromagnetic wave reflectivity of carbon fiber cement based composites. Construction and Building Materials, 64, 288-292. doi: 10.1016/j. conbuildmat.2014.04.091

19. Han B.G., Guan X.C., Ou J.P. (2007): Electrode design, measuring method and data acquisition system of carbon fiber cement paste piezoresistive sensors Sensors and Actuators A: Physical, 135(2), 360-369. doi: 10.1016/j. sna.2006.08.003

20. Zuo J.Q., Yao W., Liu X.Y., Qin J.J. (2012): Sensing properties of carbon nanotube-carbon fiber/cement nanocomposites. Journal of Testing and Evaluation, 40(5), 838-843.doi: 10.1520/JTE20120092

21. Wang H., Gao X.J., Liu J.Z., Ren M., Lu A.X. (2018): Multifunctional properties of carbon nanofiber reinforced reactive powder concrete. Construction and Building Materials, 187, 699-707. doi: 10.1016/j.conbuildmat.2018.07.229

22. Allam H., Duplan F., Clerc J.P. Amziane S., Burtschell Y. (2020): About electrical resistivity variation during drying and improvement of the sensing behavior of carbon fiber-reinforced smart concrete. Construction and Building Materials, 264, 120699. doi: 10.1016/j. conbuildmat.2020.120699

23. Sun M.Q., Liu Q.P., Li Z.Q., Hu Y.Z. (2000): A study of piezoelectric properties of carbon fiber reinforced concrete and plain cement paste during dynamic loading. Cement and Concrete Research, 30, 1593-1595. doi: 10.1016/ S0008-8846(00)00338-0

24. Ozturk M., Chung D.D.L. (2021): Enhancing the electromagnetic interference shielding effectiveness of carbon-fiber reinforced cement paste by coating the carbon fiber with nickel. Journal of Building Engineering, 41, 102757. doi: 10.1016/j.jobe.2021.102757

25. Yoon H.N., Jang D., Lee H.K., Nam I.W. (2020): Influence of carbon fiber additions on the electromagnetic wave shielding characteristics of CNT-cement composites. 
Construction and Building Materials, 269, 121238. doi: 10.1016/j.conbuildmat.2020.121238

26. Wang H., Zhang A.L., Zhang L.C., Wang Q., Yang X.H., Gao X.J., Shi F.T. (2020) Electrical and piezoresistive properties of carbon nanofiber cement mortar under different temperatures and water contents. Construction and Building Materials, 265, 30, 120740. doi: 10.1016/j. conbuildmat.2020.120740

27. Wang C., Li K.Z., Li H.J., Jiao G.S., Lu J.H., Hou D.S. (2008): Effect of carbon fiber dispersion on the mechanical properties of carbon fiber-reinforced cement-based composites. Materials Science and Engineering: A, 487(12), 52-57.doi: 10.1016/j.msea.2007.09.073

28. Wang H., Gao X.J., Liu J.Z. (2018): Coupling effect of salt freeze-thaw cycles and cyclic loading on performance degradation of carbon nanofiber mortar. Cold Regions Science and Technology, 154, 95-102. doi: 10.1016/j. coldregions.2018.07.002 